\title{
Human Enterocyte (Caco-2) Migration Is Modulated In Vitro by Extracellular Matrix Composition and Epidermal Growth Factor
}

\author{
Marc D. Basson, ${ }^{\star *}$ Irvin M. Modlin, ${ }^{\star}$ and Joseph A. Madri* \\ Departments of ${ }^{*}$ Surgery and ${ }^{\ddagger}$ Pathology, Yale University School of Medicine, New Haven, Connecticut 06510
}

\begin{abstract}
The modulation of enterocyte sheet migration was studied using Caco- 2 cells, a well-differentiated human colonic cell line. Although Caco-2 cells attached and spread equivalently over collagen types I, III, IV, and V and laminin, migration over laminin was significantly slower than migration over the collagen types. Fibronectin was a poor substrate for attachment, spreading, and migration. Epidermal growth factor (EGF) stimulated migration over laminin but did not alter Caco- 2 migration over collagen or fibronectin. This effect was independent of cell proliferation, which was stimulated equivalently on both laminin and collagen I. Expression and organization of cell surface receptors for matrix ( integrins ) were studied using antibodies specific for $\beta$ and $\alpha$ integrin subunits. Integrin surface expression was assessed by immunoprecipitation of surface ${ }^{125}$ iodinated control and EGF-treated cells. $\beta 1$ surface pools did not change substantially in any condition studied. $\alpha 1$ subunit pools were decreased after EGF treatment on collagen I but $\alpha 1$ pools increased after EGF treatment on laminin. Surface pools of $\alpha 2$ subunits were increased following EGF treatment whether cells were cultured on laminin or collagen I. However, traditional immunofluorescent and laser confocal imaging demonstrated substantial differences in the character of $\alpha 2$ subunit organization between collagen and laminin in the migrating cell front. Furthermore, a functional antibody to the $\alpha 2$ subunit inhibited EGF stimulation of migration over laminin without substantial effects on basal migration over laminin or collagen I. Thus, EGF appears to exert a matrix-specific effect on enterocyte migration by modulation of integrin expression and organization. (J. Clin. Invest. 1992. 90:15-23.) Key words: collagen • epithelial cell $\bullet$ growth factor $\bullet$ integrin $\bullet$ laminin
\end{abstract}

\section{Introduction}

The regulation of epithelial sheet migration in the gastrointestinal tract is of clinical as well as biological relevance. Processes as diverse as the normal maintenance of gut integrity, resurfacing of gastric erosions, healing of anastomoses, and resolution of inflammatory bowel disease all require mucosal restitution (1). Although migratory phenomena have been previously studied in mesenchymal and epithelial cells (2-4), the regulation of enterocyte sheet migration is unknown.

Address reprint requests to Dr. Joseph A. Madri, Department of Pathology, Yale University School of Medicine, LH 111, 310 Cedar Street, New Haven, CT 06510.

Received for publication 8 July 1991 and in revised form 3 February 1992

J. Clin. Invest.

(C) The American Society for Clinical Investigation, Inc. 0021-9738/92/07/0015/09 \$2.00

Volume 90, July 1992, 15-23
Epithelial sheet migration is a complex process in which cells in the migrating front undergo morphological changes which result in adoption of a migratory phenotype. These cells form focal contacts of increased strength at their migrating edge and transmit a deforming physical force to the less tightly adherent submarginal cells of the monolayer via cell-cell contacts and cytoskeletal elements (5). The regulation of sheet migration is likely to be as intricate as its mechanism. Patterns of distribution of matrix proteins have been hypothesized to determine pathways of cell migration in a variety of embryologic processes (6) while varying matrix substrates have been shown to modulate sheet migration in dermal epithelial, mesenchymal, and endothelial cells (2-4).

Growth factors such as transforming growth factor- $\beta$ $(\text { TGF- } \beta)^{1}$ and platelet-derived growth factor have also previously been demonstrated to affect mesenchymal and endothelial cell sheet migration in vitro (7) and dermal reepithelialization in vivo (8). A growth factor that seems likely to be involved in the regulation of enterocyte migration is epidermal growth factor (EGF). This 53 amino acid polypeptide was originally isolated from mouse submaxillary glands and subsequently from human urine. EGF is present throughout the gastrointestinal tract $(9-11)$ together with the related peptide TGF $\alpha$ which appears to activate the same receptor (12). Furthermore, the mucosal injury produced by peptic ulcer disease or Crohn's disease induces gastrointestinal stem cells to differentiate into an EGF-secreting lineage (10) while peptic ulcer disease may be associated with increased salivary secretion of EGF (13). Both EGF and EGF receptor immunoreactivity have been reported to be increased within the oxyntic mucosa of rats in which ischemic gastric ulceration had been induced (14). Long known to potentiate epithelial healing in the skin $(15,16)$, EGF has, in addition, been reported to promote gastrointestinal mucosal wound healing in animal models (13, 17). The mechanism of the EGF effect in the gut is unclear, and has previously been attributed to mitogenicity (17) or to "cytoprotection." The latter term reflects a poorly understood phenomenon described as gastroduodenal mucosal resistance to injury occurring at EGF concentrations below those required to inhibit gastric secretion (18). EGF is known to be a chemoattractant for individual rat intestinal epithelial cells (19), but its effect on the sheet migration of enterocytes released from contact inhibition in the absence of a concentration gradient has not previously been investigated.

We postulated that physiologically relevant concentrations of EGF would stimulate sheet migration of mucosal enterocytes even in the absence of a concentration gradient. In addition, since migration is known to be matrix dependent in other cell types (4), we further hypothesized that such an effect would be coregulated by enterocyte interaction with extracellu-

1. Abbreviations used in this paper: ANOVA, analysis of variance; EGF, epidermal growth factor; TGF- $\beta$, transforming growth factor- $\beta$. 
lar matrix. Cells interact with matrix by well characterized receptors known as integrins. Integrins are heterodimeric cell surface receptors composed of $\alpha$ and $\beta$ subunits that bind matrix with specificity determined jointly by both subunits (20). The integrins contain short transmembrane and cytoplasmic domains and may anchor to the cytoskeleton by association with talin (21). We therefore formulated a secondary hypothesis that alterations in expression or organization of integrins in response to varying matrix substrates and to the addition of EGF might contribute to alterations in the rate of enterocyte sheet migration.

The Caco-2 line was chosen for study. Although the Caco-2 cell line derives from a human colonic adenocarcinoma, it is remarkably well differentiated (22), expressing a luxuriant microvillar brush border with a full complement of intestinal hydrolases $(23,24)$, tight junctions (22), polar sorting of endogenous membrane proteins (22), and apically directed secretion (25). Morphologically resembling fetal colonic mucosa or adult small intestinal mucosa, the Caco- 2 cell has frequently been used to model normal human intestinal mucosa $(25,26)$. The effect of matrix substrates and physiologically relevant concentrations of EGF on the rate of Caco-2 sheet migration were investigated using a "fence" migration assay previously developed and characterized in our laboratory (4). The potential mediation of the EGF effect by alterations in integrin cell surface pools was investigated by immunoprecipitation of surface-labeled cell lysates using integrin subunit-specific antibodies. The contribution of alterations in the $\alpha 2$ subunit was further tested by specific blockade using a functional antibody. Finally, EGF modulation of integrin organization was studied using traditional immunofluorescent and confocal imaging techniques.

\section{Methods}

Cells. The Caco- 2 cells used for these studies represented a clonal subpopulation which were a generous gift of Dr. Mark Mooseker (Department of Biology, Yale University, New Haven, CT). The cells were maintained at $37^{\circ} \mathrm{C}$ in $5 \% . \mathrm{CO}_{2}$ in Dulbecco's minimal essential medium containing $10 \%$ fetal calf serum, $10 \mu \mathrm{g} / \mathrm{ml}$ transferrin (Boehringer Mannheim Corp., Indianapolis, IN), 2 mM glutamine, 1 $\mathrm{mM}$ pyruvate, $10 \mathrm{mM}$ Hepes, $100 \mathrm{U} / \mathrm{ml}$ penicillin $\mathrm{G}$, and $0.1 \mathrm{mg} / \mathrm{ml}$ streptomycin. All studies were performed on cells within eight passages. The EGF used for these studies was human recombinant EGF (Upstate Biotechnology, Inc., Lake Placid, NY).

Matrix proteins. Laminin and type IV collagen were purified from lathyritic murine Engelbreth-Holm-Swarm tumor (27). Collagen types I, III, and V were isolated and purified as previously described (27), and plasma fibronectin was purified from fresh human plasma by gelatin-Sepharose and molecular sieve chromatography (27). Fibrinogen was obtained from Calbiochem-Behring Diagnostics (La Jolla, CA ). Bacteriologic plastic dishes (Falcon Labware, Becton, Dickinson, \& Co., Oxnard, CA) were coated with saturating concentrations of matrix substrates as previously described (27).

Antibodies. For an initial survey of the Caco- 2 integrin set, a battery of antiintegrin antibodies was employed for immunoprecipitation studies. Antibodies to the $\beta 1$ and $\beta 4$ integrin subunits were generous gifts of Drs. C. Buck (Wistar Institute, Philadelphia, PA) (28) and S. J. Kennel (Oak Ridge National Laboratory, TN) (29). Antibodies to the $\beta 3$ integrin subunit were raised in rabbits against the $\mathrm{COOH}$-terminal 37 amino acids of the human integrin subunit. Antibodies to the $\alpha 1$ integrin subunit were a generous gift from Dr. Martin Hemler (Dana Farber Cancer Institute, Boston, MA) (30). Antibodies to the $\alpha 2$ and $\alpha 3$ subunits were purchased from Telios Pharmaceuticals Inc. (San
Diego, CA). Antibodies to $\alpha 4$ were a gift from Dr. M. Gallatin (ICOS, Bothell, WA). Two antibodies to $\alpha 5$ were tested, gifts of Drs. K. Yamada (National Institutes of Health, Bethesda, MD) (31) and C. Damsky (University of California, San Francisco, CA) (32). Antibodies to $\alpha 6$ were gifts from Dr. Damsky and Dr. A. Sonnenberg (Netherlands Red Cross Blood Transfusion Service, Amsterdam, The Netherlands) (33). For functional studies of migration, the antibody to $\alpha 2$ was used at a dilution of 1:1,000 (at an approximate protein concentration of $1 \mu \mathrm{g} / \mathrm{ml}$ ) and reapplied in fresh media every second day. Control studies were performed with normal mouse $\mathrm{IgG}$ at $1 \mu \mathrm{g} / \mathrm{ml}$ protein concentration. For double labeling immunocytochemical studies, a rabbit polyclonal antibody to the $\alpha 2$ subunit was employed, a generous gift from Dr. Buck. A goat anti-rabbit secondary antibody conjugated to tetramethyl rhodamine (Cappel Laboratories, Malvern, PA) was employed for this purpose. A mouse antivinculin antibody (Sigma Chemical Co., St. Louis, MO) was used to stain for vinculin, with secondary labeling via a goat anti-mouse antibody conjugated to fluorescein (Cappel).

Assays. Cell adhesion was measured as previously described (4). Adhesion assays were performed using $35-\mathrm{mm}$ bacteriologic plastic dishes which had been precoated with saturating quantities of matrix substrate and then blocked with heat-inactivated bovine serum albu$\mathrm{min}$. Cell area was measured using morphometric analysis software to directly quantify cell area after staining with hematoxylin and eosin. DNA synthesis was assessed by $\left[{ }^{3} \mathrm{H}\right]$ thymidine uptake and counting of nuclei with overlying silver grains after a photographic emulsion coating (Ilford K5.D; Polysciences Inc., Warrington, PA) was applied and developed. Migration was quantitated as previously described (4). Briefly, cells were plated to confluence within stainless steel "fences" placed on matrix-precoated $35-\mathrm{mm}$ bacteriologic plastic dishes. After the cells had achieved confluence the fences were removed, permitting outward migration. After $6 \mathrm{~d}$, cells were fixed in situ and the area of the confining fence was subtracted from the area covered by the cells.

For investigations of integrin surface pool expression and organization, Caco-2 cells grown on collagen I and laminin were pretreated for $12 \mathrm{~h}$ with a dose of EGF $\left(30 \mathrm{ng} / \mathrm{cm}^{3}\right)$ previously identified as maximal in stimulation of Caco-2 migration. Cycloheximide pretreatment, when used, was with $500 \mu \mathrm{M}$ cycloheximide for $30 \mathrm{~min}$ before EGF treatment and then simultaneously with EGF exposure.

By methods previously described (34), surface iodination was performed with $\mathrm{Na}^{125} \mathrm{I}$ and lactoperoxidase and cells were then lysed and immunoprecipitation was performed using Sepharose-conjugated protein A or G (Pharmacia LKB, Uppsala, Sweden). Surface biotinylation and immunoprecipitation for $\alpha 2$ integrin subunit was performed in suspended cells by the protocol recommended by the supplier of the antibody (Telios Pharmaceuticals). Immunoprecipitates were resolved under nonreducing conditions by SDS-PAGE using a 6\% gel with a $3.5 \%$ stacking gel. Autoradiographic exposures employed Kodak AR-5 film at $-70^{\circ} \mathrm{C}$ for $1-10 \mathrm{~d}$. All exposures quantitated were within the linear range of the film and exposure.

Staining techniques. For immunofluorescent staining, cells were fixed with periodate-lysine-paraformaldehyde fixative and permeabilized with $0.2 \%$ Triton $\mathrm{X}-100$. After nonspecific staining had been blocked with $4 \%$ bovine serum albumin and normal mouse IgG, primary antibodies to the integrin $\alpha 2$ subunit and to vinculin were applied and then visualized using fluorescein-conjugated anti-mouse IgG (Cappel) or a goat anti-rabbit secondary antibody conjugated to tetramethyl rhodamine (Cappel) as appropriate and examined using a Zeiss Axiophot Photomicroscope. All photomicrographs were taken using a standard 60-s exposure. Confocal imaging and interference reflectance microscopy were performed using a confocal microscope (CRC 600; Bio-Rad Laboratories, Richmond, CA).

Statistics. For assessments of cell adhesion, spreading, and migration, statistical analysis was performed by unpaired $t$ test or analysis of variance at $95 \%$ confidence where appropriate, using the PC-SAS software package (Statistical Analysis Institute, Chicago, IL). Band intensity in autoradiographs after immunoprecipitation and SDS-PAGE were quantitated using a digitizing scanning densitometer (Bioimage; 


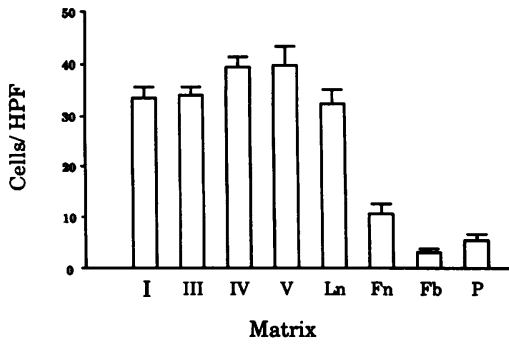

$(L n)$, fibronectin $(F n)$, fibrinogen $(F b)$, and tissue culture plastic $(P)$. Data represent mean \pm standard error $(n=30)$.

Hoefer Scientific Instruments, San Francisco, CA). All immunoprecipitation experiments were repeated at least three times with similar results. Changes $<10 \%$ were considered insignificant. Numerical data are reported here as mean \pm standard error for cell culture experiments and as absolute range for autoradiographic densitometry.

\section{Results}

Attachment, spreading, and migration of Caco-2 cells are modulated by extracellular matrix proteins. Caco-2 cells demonstrated similarly good adhesion (Fig. 1) and spreading (Fig. 2) on collagen types I, III, IV, and V and on laminin. Adhesion and spreading were more modest over fibronectin and tissue culture plastic while adhesion to fibrinogen was poor (Figs. 1 and 2). In contrast to adhesion and spreading on laminin, Caco-2 cell migration over laminin was $68.3 \pm 1.6 \%$ ( significant by analysis of variance (ANOVA) at $P<0.05$ ) of that over collagen I in initial characterizations of the effect of matrix substrate on the rate of enterocyte sheet migration. Migration over collagen I was similar to that of Caco-2 cells over the other collagen types studied (Fig. 3). Similar differential rates of migration were observed after pretreatment with a replication-inhibiting dose of mitomycin C ( $20 \mu \mathrm{g} / \mathrm{cm}^{3}$ for $2 \mathrm{~h}$ ) (laminin/ collagen $\mathrm{I}=76.3 \pm 4.2 \%$ ), consistent with previous studies in other cell types $(2,7)$ and suggesting that the effect of matrix on Caco-2 migration was independent of proliferation.

EGF selectively modulates Caco-2 cell migration. EGF stimulated Caco-2 migration over laminin in a dose-dependent manner with maximal $2.1 \pm 0.2$-fold increase at $30 \mathrm{ng} / \mathrm{cm}^{3}$ (Fig. 4). After mitomycin C pretreatment $\left(20 \mu \mathrm{g} / \mathrm{cm}^{3}\right.$ for $\left.2 \mathrm{~h}\right)$ to inhibit proliferation, $20 \mathrm{ng} / \mathrm{cm}^{3}$ EGF nevertheless produced a 2.6 \pm 0.1 -fold increase in migration. In contrast, epidermal growth factor had no effect on Caco-2 migration over collagen I

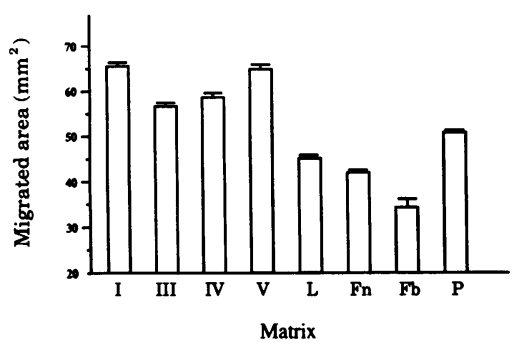

Figure 3. Caco-2 sheet migration on different matrix substrates. Area covered by enterocyte sheet migration varies significantly $(P<0.05$ by ANOVA) between cells grown on collagen types I, III, IV, and V and cells grown on lam$\operatorname{inin}(L n)$, fibronectin $(F n)$, fibrinogen $(F b)$, and tissue culture plastic $(P)$.

or fibronectin. Specifically, migration during treatment with $30 \mathrm{ng} / \mathrm{cm}^{3} \mathrm{EGF}$ resulted in $86.0 \pm 7.2 \%$ of untreated migration over collagen I and $78.6 \pm 11.5 \%$ of untreated migration over fibronectin $(P>0.05$ for both). Strikingly, although EGF did not stimulate migration over collagen I, EGF did stimulate $\left[{ }^{3} \mathrm{H}\right]$ thymidine uptake (proliferative activity) equivalently on both collagen I and laminin (Fig. 5, $a$ and $b$ ).

EGF selectively modulates Caco-2 cell integrin expression. Since stimulation of Caco-2 migration by EGF appeared matrix dependent, we hypothesized that this process might be mediated by EGF effects on Caco-2 integrin expression or organization. Initial characterization of the Caco-2 integrin repertoire using antibodies specific for the $\beta 1, \beta 3$, and $\beta 4$ subunits demonstrated only the $\beta 1$ integrin subunit (data not shown). Immunoprecipitation with probes specific for the $\alpha 1, \alpha 2, \alpha 3, \alpha 4, \alpha 5$, and $\alpha 6$ subunits demonstrated intense bands for $\alpha 1$ and $\alpha 2$ and a very weak band for $\alpha 6$ which required prolonged autoradiographic exposure times for visualization. The $\alpha 1$ subunit was present as a doublet which may represent precursor and native forms (35, M. H. Hemler, personal communication). No immunoreactivity could be precipitated using an antibody to the $\alpha 4$ subunit. Faint bands visualized using antibodies to $\alpha 3 \beta 1$ and $\alpha 5 \beta 1$ could have represented small amounts of these integrin heterodimers on the cell surface (data not shown). After Sepharose beads (Pharmacia LKB) conjugated to collagen I and laminin had been incubated with ${ }^{125}$ iodinated cell lysates, elution from each matrix with $2 \mathrm{M} \mathrm{NaCl}$ yielded proteins which could be immunoprecipitated by antibodies to $\alpha 1$ and $\alpha 2$ integrin subunits (data not shown). Thus, both $\alpha 1 \beta 1$ and $\alpha 2 \beta 1$ integrin heterodimers present on Caco- 2 cells are capable of binding to collagen I or laminin.

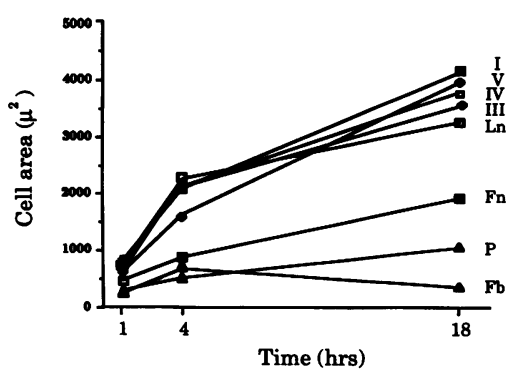

area after staining with hematoxylin and eosin. Abbreviations are as in Fig. 1. Data represent mean \pm standard error $(n=100)$.
Figure 2. Rates of individual Caco-2 cell spreading on different matrix substrates. Indimeasured at 1,4 , and $18 \mathrm{~h}$ after plating on various matrix substrates using morphometric analysis software vidual cell areas were

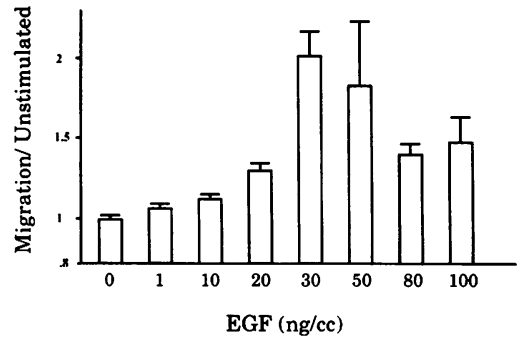

Figure 4. Stimulation of Caco-2 sheet migration over laminin by EGF. Treatment with increasing concentrations of EGF for 6-d results in a dose-dependent increase in migrated area. Stimulation with all concentrations $\geq 10 \mathrm{ng} / \mathrm{cm}^{3}$ EGF resulted in significant increases in migration compared with control $(P<0.05$ by ANOVA). 

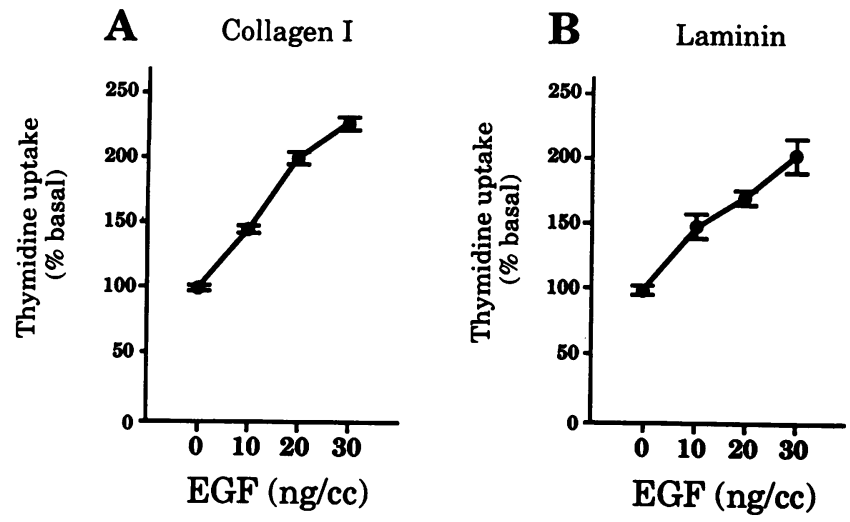

Figure 5. EGF stimulation of $\left[{ }^{3} \mathrm{H}\right]$ thymidine uptake by Caco- 2 cells on collagen I and laminin. Treatment of Caco-2 cells on collagen I $(A)$ and laminin $(B)$ with EGF results in equivalent increases in DNA synthesis, assessed by $\left[{ }^{3} \mathrm{H}\right]$ thymidine uptake and counting of nuclei with overlying silver grains after a photographic emulsion coating had been applied and developed. Data represent mean \pm standard error, $n=100$.

To investigate EGF modulation of cell surface integrin pools, Caco-2 cells cultured on collagen I or laminin were surface iodinated and lysed without or with 12-h EGF ( $30 \mathrm{ng}$ / $\mathrm{cm}^{3}$ ) pretreatment. Initial studies used immunoprecipitation with an antibody to the $\beta 1$ subunit, which coprecipitated all associated $\alpha$ subunits. SDS-PAGE, autoradiography, and densitometric quantification revealed only a $37-41 \%$ increase in the $\beta 1$ subunit pool following EGF treatment on laminin and no substantial change after EGF treatment on collagen I (Fig. 6 $A$ ). However, substantial alterations of cell surface immunoreactivity for $\alpha 1$ and $\alpha 2$ on both matrices were observed after immunoprecipitation with antibodies specific for these $\alpha$ integrin subunits. Densitometric assessment of the $\alpha$ integrin subunit surface pool revealed an $80-81 \%$ decrease with EGF treatment in cells cultured on collagen I, but $\alpha 1$ increased after EGF

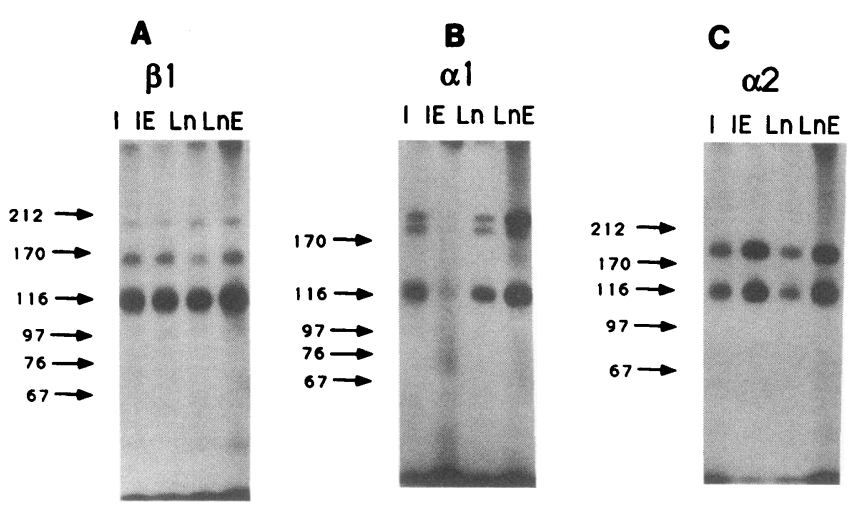

Figure 6. Alterations of $\beta 1, \alpha 1$, and $\alpha 2$ surface pools in Caco- 2 cells with matrix substrate and EGF treatment. Caco- 2 cells were grown on collagen $I(I)$ and laminin $(L n)$ in the absence and presence of 30 $\mathrm{ng} / \mathrm{cm}^{3}$ EGF ( $I E$ and $L n E$ ). After surface ${ }^{125}$ iodination, cell lysis, and immunoprecipitation with antibodies specific for integrin $\beta 1, \alpha 1$, and $\alpha 2$ subunits, integrins were resolved by SDS-PAGE and imaged by autoradiography. Although total $\beta 1$ surface pools do not change dramatically $(A), \alpha 1$ surface pools $(B)$ decrease after EGF treatment on collagen I but increase on laminin while $\alpha 2$ surface pools $(C)$ increase after EGF treatment on both matrix substrates.

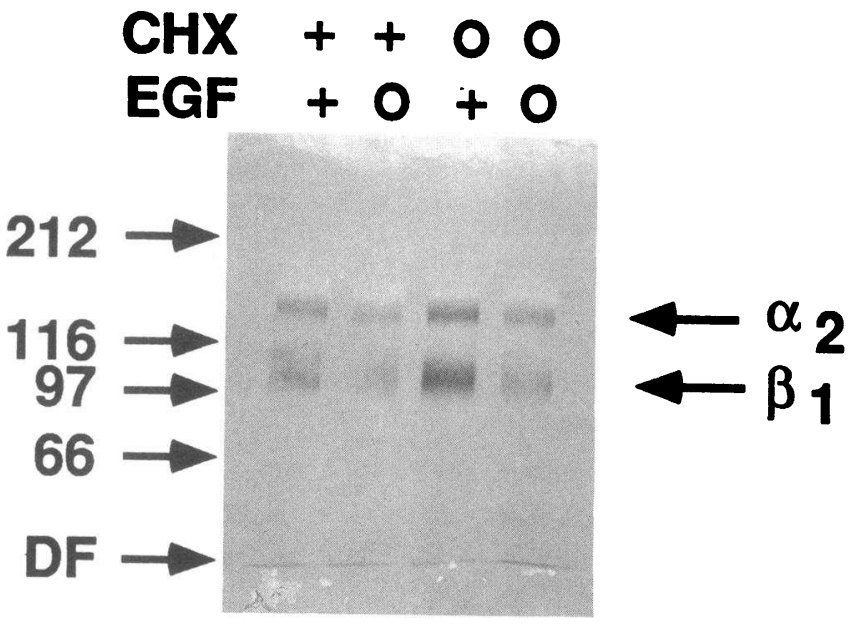

Figure 7. Effect of cycloheximide on basal and EGF-stimulated $\alpha 2$ integrin subunit pools. Caco- 2 cells were grown on laminin in the absence and presence of $30 \mathrm{ng} / \mathrm{cm}^{3}$ EGF or $500 \mu \mathrm{M}$ cycloheximide. After suspension and surface biotinylation, cell lysis, and immunoprecipitation with antibodies specific for the integrin $\alpha 2$ subunit, integrins were resolved by SDS-PAGE. The proteins were transferred to nitrocellulose by electroblotting and visualized by avidin-biotin staining. $\alpha 2$ pools increase in response to EGF, but this increase does not occur in EGF-treated cells which have also been exposed to cycloheximide.

treatment in cells cultured on laminin (1.6-5.7 fold increase, Fig. $6 \mathrm{~B}$ ). In contrast, $\alpha 2$ band intensity increased with EGF treatment on both collagen I and laminin (1.6-2.0-fold increase on collagen I; 2.9-4.4-fold on laminin, Fig. $6 C$ ).

To control for differential accessibility of integrins on free and adherent cell surfaces, the ability of EGF to increase $\alpha 2$ integrin subunit surface immunoreactivity in Caco- 2 cells on laminin was confirmed using biotinylation to surface label Caco-2 cells which had been suspended after culture on laminin and EGF treatment ( Fig. 7). Furthermore, pretreatment for $30 \mathrm{~min}$ with cycloheximide followed by simultaneous EGF and cycloheximide exposure substantially inhibited the EGF effect on a2 surface immunoreactivity.

Antibodies directed against $\alpha 2 \beta 1$ integrin selectively modulate Caco-2 cell migration. The availability of a specific functional antibody to the $\alpha 2$ integrin subunit permitted further analysis of the role played by alterations in the $\alpha 2 \beta 1$ heterodimer in EGF-stimulated migration. This antibody did not significantly alter Caco-2 migration over laminin $(97.7 \pm 0.6 \%$ of untreated migration) but substantially inhibited EGF-stimulated migration $(63.5 \pm 3.1 \%$ of unblocked EGF-stimulated migration, $P<0.001$, Fig. 8 ). Migration over collagen $\mathrm{I}$ in the presence of the antibody was $88 \pm 10 \%$ of migration without the antibody. This was not statistically significant. After treatment with EGF, antibody-blocked Caco-2 migration over collagen I was $77.2 \pm 4.4 \%$ of unblocked EGF-treated migration ( $P$ $<0.001$, Fig. 8). Parallel studies using normal mouse $\operatorname{IgG}$ at similar protein concentrations failed to inhibit migration in any condition (data not shown).

Caco-2 morphology and integrin organization are modulated by extracellular matrix and EGF. Organization of the $\alpha 2$ subunit was investigated by light microscopy and immunofluorescent staining of static and migrating monolayers on collagen I and laminin without and with $30 \mathrm{ng} / \mathrm{cm}^{3}$ EGF. Confocal laser scanning microscopy was also used to distinguish basal 


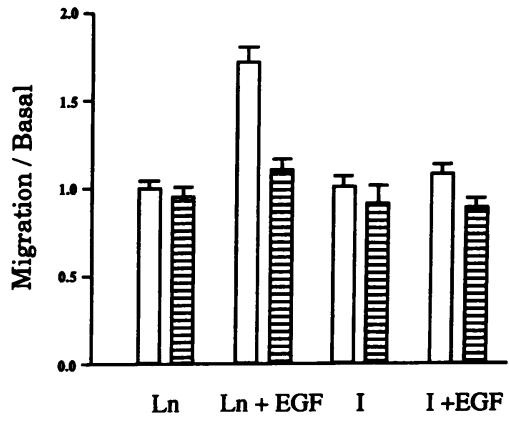

Figure 8. Effect of $\alpha 2$ blockade on Caco-2 migration. The effect on monolayer expansion of blockade with a function antibody to the integrin $\alpha 2$ subunit ( hatched bars) was compared to unblocked migration (open bars) in Caco-2 monolayers grown on laminin $(L n)$ and collagen $I(I)$ in the

absence and presence of $30 \mathrm{ng} / \mathrm{cm}^{3} \mathrm{EGF}(+E G F)$. Data are normalized to unstimulated migration over laminin and collagen I respectively and represent mean \pm standard error, $n \geq 12$. Effects of $\alpha 2$ blockade are significant by unpaired $t$ test for conditions LE ( $P$ $<0.001)$ and $\operatorname{IE}(P<0.05)$.

from apical and intracellular staining. Staining for $\alpha 2$ was observed in all conditions in a perinuclear distribution. In static monolayers and within the center of the migrating monolayers, cell morphology appeared similar at the light level and cytoplasmic $\alpha 2$ staining was observed in a granular and pan-cytoplasmic pattern which did not vary substantially with matrix or EGF treatment (data not shown). However, marked differences were demonstrated in morphology and $\alpha 2$ staining patterns in cells at the migrating front.

On conventional light microscopy of migrating Caco- 2 cells on collagen I, the cells comprising the migrating front were observed to have spread substantially in the direction of migration and to have developed scalloped edges (Fig. $9 a$ ). After exposure to EGF on collagen I, migrating Caco-2 cells appeared similar to untreated cells on collagen I (Fig. $9 b$ ). On laminin, cells at the migrating front did not appear to spread as much as cells on collagen I (Fig. $9 c$ ). However, after EGF treatment, the cells at the migrating front over laminin spread substantially more than in the unstimulated state (Fig. $9 d$ ).

Immunofluorescent study of $\alpha 2$ staining patterns within the cells of the migrating front on collagen I (Fig. 10a) demonstrated a predominantly perinuclear granular staining pattern similar to a distribution within the endoplasmic reticulumGolgi apparatus. Faint punctate fluorescence was observed throughout the cytosol toward the leading edge of the cells. After EGF treatment, increased immunofluorescent staining for $\alpha 2$ was observed both in the perinuclear distribution and within the cytoplasmic compartment. Some punctate staining was observed in the leading lamellopodia of the migrating cells (Fig. $10 b$ ). Immunofluorescent $\alpha 2$ staining in Caco-2 cells migrating over laminin (Fig. $10 \mathrm{c}$ ) revealed perinuclear staining and weak granular staining was observed throughout the cytosol of the lamellopodia. After EGF treatment, however, staining increased in intensity but also appeared to change in organization (Fig. $10 d$ ). Increased staining was observed in both the perinuclear and cytosolic distribution. However, in addition, marked staining was observed at areas of contact between cells at the migrating front as well as substantially increased staining at the spread lamellopodial edges of the migrating cells.

Laser confocal scanning microscopy was used to confirm the basal localization of the observed $\alpha 2$ integrin subunit staining (data not shown). To further assess the relevance of the observed immunofluorescent $\alpha 2$ integrin subunit staining, interference reflectance microscopy and double labeling studies with vinculin were performed. The basal $\alpha 2$ integrin staining appeared concentrated in areas of focal contact between cells and matrix by interference reflectance microscopy (data not shown). Furthermore, double immunostaining for the $\alpha 2$ integrin subunit and vinculin demonstrated colocalization of the cytoplasmic $\alpha 2$ staining with vinculin staining (Fig. 11, $a$ and $b$ ).

\section{Discussion}

The Caco-2 line is remarkably well differentiated (22) and resembles primary enterocytes $(25,26)$. The integrin repertoire of Caco-2 cells is consistent with normal human intestinal mucosa $(36,37)$. Thus, the Caco-2 line seems a reasonable model from which cautious inferences may be drawn about normal physiology.
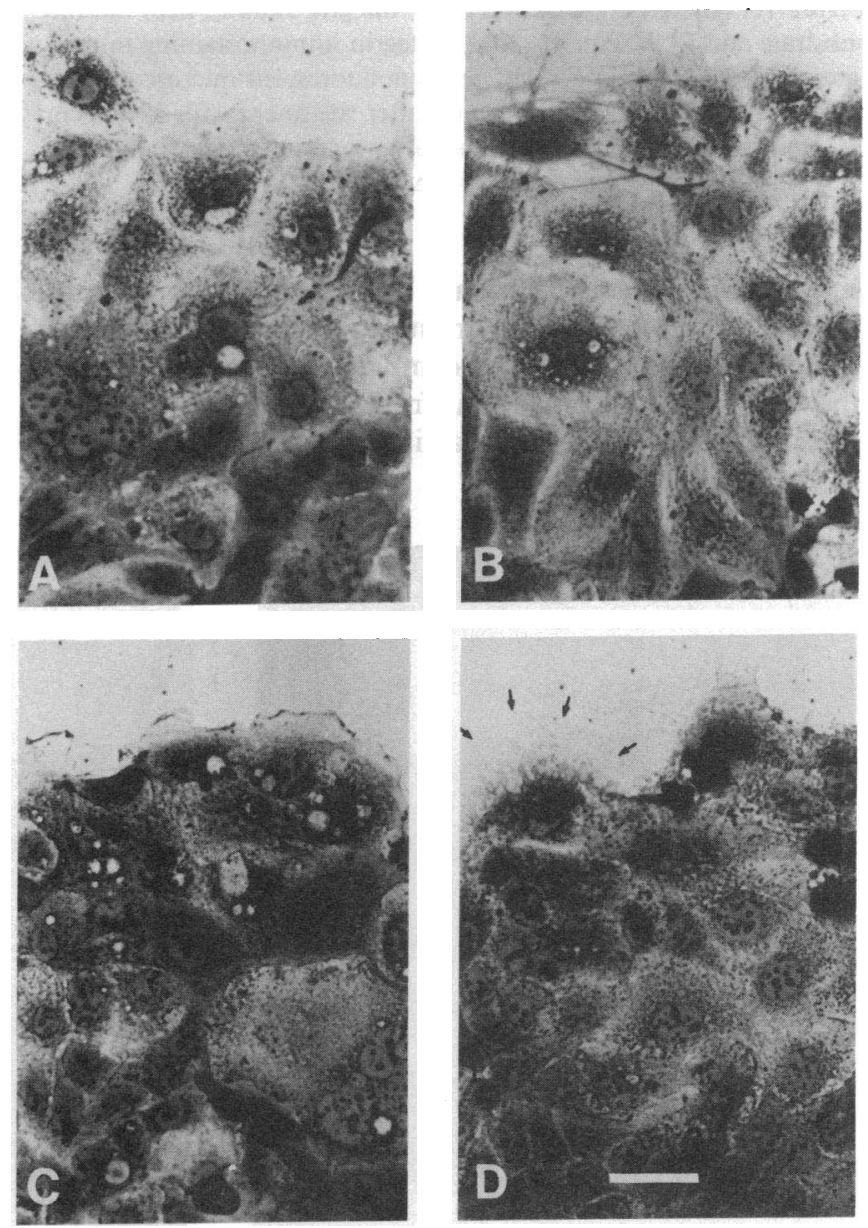

Figure 9. Altered morphology of migrating Caco-2 cells with matrix substrate and EGF. Distinctively spread morphology of migrating Caco- 2 cells by light microscopy $(\times 200)$ is depicted on collagen I without $(A)$, and with treatment with $30 \mathrm{ng} / \mathrm{cm}^{3} \mathrm{EGF}(B)$. On laminin $(C)$, cells at the migrating front spread very little. However, after treatment with $30 \mathrm{ng} / \mathrm{cm}^{3}$ EGF, Caco-2 cells at the migrating front on laminin spread much more substantially $(D)$. Arrows in panel $D$ indicate the thinly spread margin of a migrating cell. Scale bar represents $50 \mu \mathrm{m}$. 

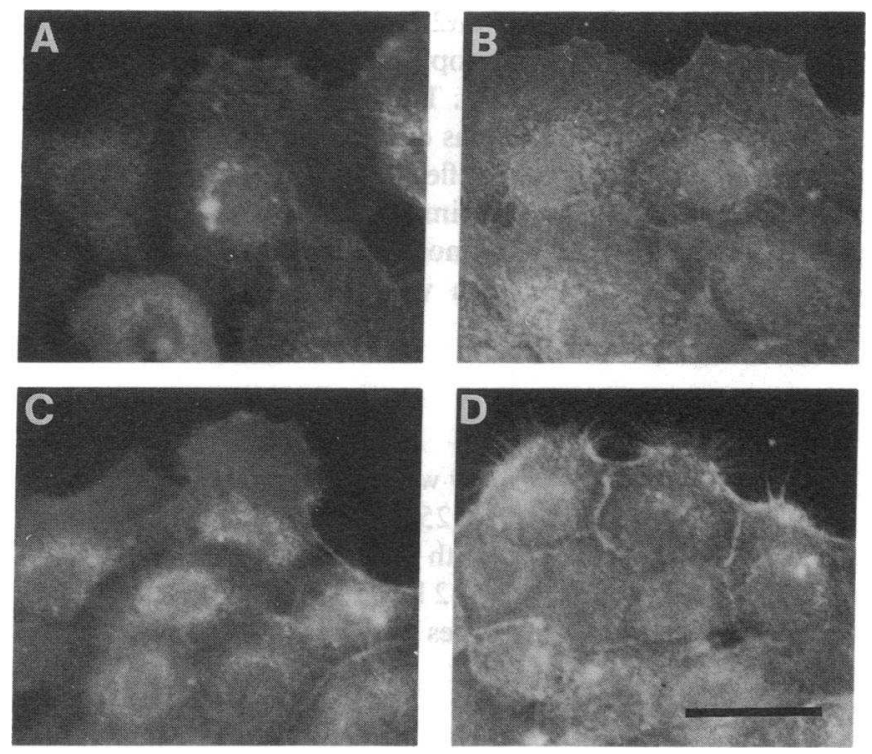

Figure 10. Altered organization of $\alpha 2$ integrin subunit with matrix substrate and EGF. Patterns of $\alpha 2$ integrin immunostaining in migrating Caco- 2 cells imaged by immunofluorescent microscopy are shown on collagen I $(A)$, collagen I after treatment with $30 \mathrm{ng} / \mathrm{cm}^{3}$ $\operatorname{EGF}(B)$, laminin $(C)$, and laminin after treatment with $30 \mathrm{ng} / \mathrm{cm}^{3}$ EGF $(D)$. Scale bar represents $50 \mu \mathrm{m}$.

Epithelia generally resurface by sheet migration, which is likely to differ substantially from movement of isolated cells. Epithelial sheet migration is a complex process in which cells at the leading edge of a migrating front adhere to the underlying matrix differently than submarginal cells, exerting tension on the monolayer via cell-cell adhesions and cytoskeletal linkages and expanding the monolayer over the epithelial defect (5). Others have investigated motility (38) and chemotaxis (19) of individual cells. Previous attempts to model sheet migration have generally involved the radial migration of cells from tissue explants (39-41) or the creation of wounds in cell monolayers $(42,43)$ or intact tissues $(8,13-17,43)$. Studies of intact tissue or tissue explants may be difficult to control while cell injury occurring in wounding may release intracellular bioactive agents which confuse the assay (42). Barrandon (3) described growth of cultured epidermal cell colonies but studied small proliferating colonies. The "fence" migration assay is designed to investigate sheet migration over time under controlled conditions without cell injury.

Using the Caco- 2 cell, we therefore investigated the regulation of enterocyte migration by extracellular matrix and EGF and the modulation of the EGF effect by alterations in integrin expression and organization. This study demonstrates that Caco-2 enterocyte sheet migration is slower over laminin, fibronectin, or fibrinogen than over collagen I, III, IV or V. Mitomycin pretreatment studies and the matrix-independence of proliferation demonstrated that this modulation of sheet migration was not due to an effect of matrix on cell proliferation. Human EGF stimulated Caco-2 migration over laminin, but not over other matrix substrates. This phenomenon was independent of the mitogenic effect of EGF, which is independent of matrix and which was blocked by mitomycin without inhibiting the EGF effect on migration. The effect of EGF on migration appears related to modulation of the $\alpha 2$ subunit since a functional antibody to $\alpha 2$ blocks the EGF effect.

Although integrin modulation of enterocyte migration or adhesion has not previously been investigated, modulation of migration by matrix is not surprising since cells must bind to

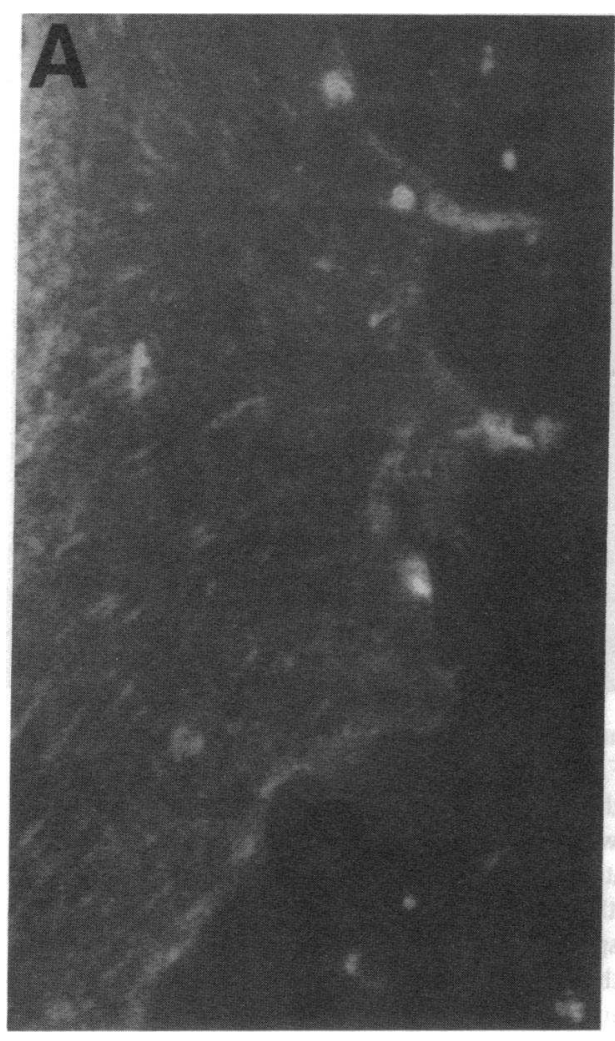

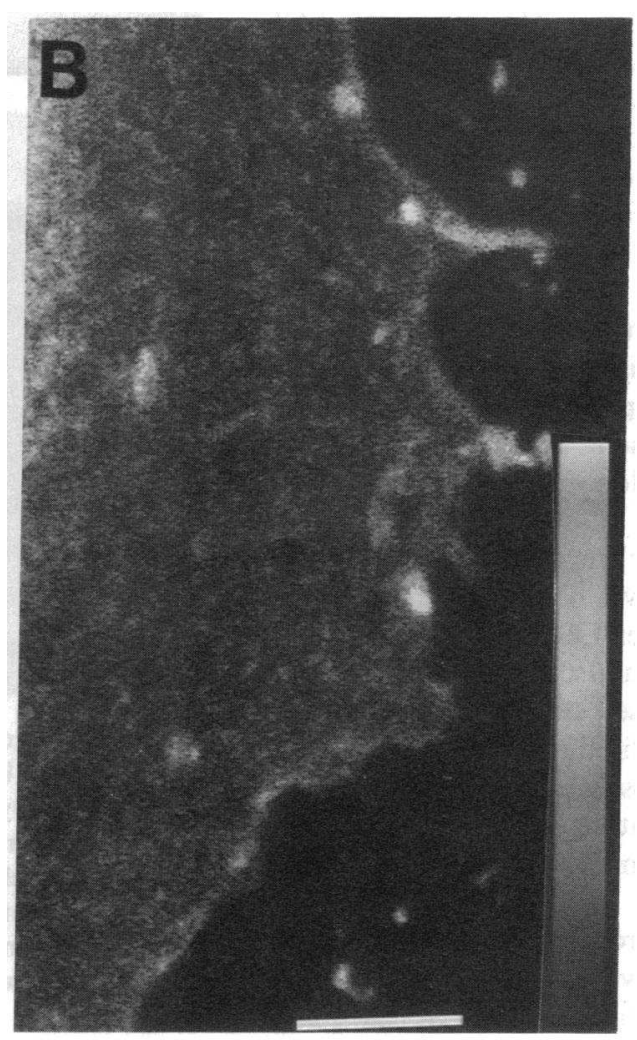

Figure 11. Colocalization of $\alpha 2$ integrin subunit and vinculin. Caco- 2 cells grown on laminin in the presence of EGF were permeabilized and stained simultaneously with antibodies to the $\alpha 2$ integrin subunit and to the cytoskeletal element vinculin. Secondary antibodies conjugated to Texas red and fluorescein were visualized by laser scanning confocal microscopy. $A$ represents staining for the $\alpha 2$ integrin subunit and $B$ represents staining for vinculin in the same cell. The scale bar represents $10 \mu \mathrm{m}$ and the pattern of pseudocolor staining is represented in the color wedge with the most intense staining corresponding to the top of the color wedge. 
and exert tension on their substratum in order to move (44). Enterocytes thus resemble human epidermal cells which, although they bind differently to matrix than enterocytes, are also likely to interact with matrix via integrins. The $\alpha 2 \beta 1$ integrin has been implicated in human epidermal cell adhesion to collagen and laminin (45) and may also be important for cellcell adhesion $(45,46)$. This would be consistent with the localization of $\alpha 2$ to the lateral margins of migrating enterocytes observed on laminin after EGF treatment. Organization of $\beta 1$ integrins into focal contacts accompanies development of migratory competence in primary human keratinocytes with serial passage, but the $\alpha$ subunits associated with the $\beta 1$ subunit were not investigated in that study (47). That matrix regulates migration independently of proliferation is also consistent with previous findings that mucosal restitution in vivo is too rapid to be mediated by proliferation (1) and that epidermal migration occurs from human skin explants during mitotic arrest (48).

The effect of EGF on enterocyte sheet migration has not previously been studied. However, this demonstration that EGF can stimulate enterocyte sheet migration independently of proliferation is compatible with previous studies of enterocyte chemotaxis and epidermal cell motility. EGF has been shown to attract isolated rat enterocytes (19) as well as an oral epithelial cell line (49). EGF promotes migration of epithelial cells from rabbit corneal explants and porcine skin explants (40) and human epidermal cell colony expansion (3). Such phenomena occur too rapidly for proliferation as the sole explanation, suggesting that EGF truly alters cell motility (3). This study suggests that EGF promotes enterocyte sheet migration primarily by altering cell interaction with underlying matrix.

EGF is known to promote adhesion of some nonenterocyte cell lines to plastic or fibronectin substrata (50) while in other cell lines EGF has been reported to promote anchorage-independent growth (51). The effects of integrins and matrix proteins on these processes has not been well investigated.

The matrix-specific effect of EGF on laminin suggests mediation by alterations in the cell surface receptors for matrix. Since both $\alpha 1 \beta 1$ and $\alpha 2 \beta 1$ integrins may serve as collagen and/ or laminin receptors in different cell types $(45,52)$, differential modulation of surface pools and organization of either heterodimer by EGF could account for a differential stimulation of migration. The specificity of individual integrin heterodimers could also be altered in response to environment and cell status (53), although this was not investigated in this study.

That antibody to the $\alpha 2$ subunit inhibits EGF-stimulated migration over laminin without altering basal migration implicates $\alpha 2$ in EGF stimulation of Caco- 2 migration. A contribution of $\alpha 1$ cannot be ruled out, absent a functional antibody to human $\alpha 1$. The $\alpha 6 \beta 1$ integrin is a laminin receptor (32), but its slight cell surface immunoreactivity in Caco- 2 cells suggests that little $\alpha 6 \beta 1$ is present on their surface.

The EGF-induced change in $\alpha 2$ immunoreactivity requires protein synthesis since it is inhibited by cycloheximide. This may represent true induction of new $\alpha 2$ synthesis or the existence of another protein which may participate in $\alpha 2$ transport to the cell surface. EGF has also been reported to selectively alter mRNA stability (54). If EGF changed integrin subunit mRNA stability, this could also contribute to the changes in integrin subunit protein reported here. The matrix-dependent modulation by EGF of $\alpha 1$ surface pools could also represent modulation of translation or mRNA degradation, transcrip- tional effects, alterations in transport to the cell surface or increased active removal of the integrin subunit from the cell surface, by proteases or internalization. Such mechanisms have been postulated for other integrins and cells (55-57) but are beyond this investigation.

While EGF increased $\alpha 2$ subunit surface pools similarly on collagen and laminin, EGF had a greater effect on $\alpha 2$ organization in migrating cells on laminin than on collagen. The observed increase on laminin in lateral $\alpha 2$ staining as well as lamellopodial edge staining is consistent with keratinocyte $\alpha 2$ organization $(45,46)$. Colocalization of basal $\alpha 2$ staining with vinculin and with focal contacts further suggested that basal $\alpha 2$ was significant for cell-matrix interactions.

These findings contrast with previous data in mesenchymal cells. In vascular smooth muscle and endothelial cells (58), other growth factors (platelet-derived and TGF $\beta 1$ ) modulate only surface expression of integrins while organization is primarily regulated by matrix. In Caco- 2 cells, EGF appears to modulate both surface pool size and organization of some integrins on collagen I and laminin.

The stimulation of migration by EGF over laminin seems likely to be physiologically relevant. Laminin is a primary constituent of basement membranes and the significant polymeric component of some newly formed basement membranes which lack collagen IV (59). Since embryonic morphogenetic migration ceases with cell differentiation (6) and since renewed cell migration during wound healing often coincides with temporary dedifferentiation (60), it is noteworthy that basement membrane proteins such as laminin have previously been shown to alter morphology and promote differentiation in vitro of fetal rat enterocytes (61), rat intestinal cell lines (62), and the colonic cancer line $\operatorname{MOSER}_{\mathrm{SF}}(63)$.

The EGF concentrations studied compare with those which bathe human gastrointestinal mucosa (13) and which are active in other systems (64). Wright et al. (10) have reported that enterocyte stem cells in humans with peptic ulcers or Crohn's disease differentiate to a novel EGF-secreting lineage. Duodenal Brunner's glands (9) and intestinal cell lines (11) also exhibit EGF immunoreactivity. Although luminal EGF does not promote mucosal hyperplasia in the intact gut (65), a breach in mucosal integrity facilitates absorption and activity of luminal EGF (17) which may potentiate the effects of EGF secreted within the mucosa (10). Indeed, EGF may influence enterocyte proliferation in an autocrine loop (11). EGF is therefore potentially significant for the regulation of the gastrointestinal response to injury. Beauchamp et al. have demonstrated that TGF $\alpha$, which binds the same receptor, is also active in the gut (12), perhaps also in autocrine fashion (66).

EGF promotes ulcer healing in rats (17) and potentiates reepithelialization of intestinal serosal patches (67). Such effects may be mediated by increased enterocyte migration as well as proliferation. EGF stimulates chemotactic movement along a chemical gradient (19), but the current data suggest that an EGF gradient need not be postulated to explain EGF stimulation of gastrointestinal mucosal sheet migration during wound healing.

These data therefore suggest that EGF stimulates enterocyte sheet migration in a matrix-specific manner in addition to stimulating proliferation. The effect of EGF on migration seems likely to be modulated at least in part by modulation of the surface pool size and organization of the $\alpha 2 \beta 1$ integrin. Alterations in other integrins by EGF may also prove signifi- 
cant. Rapid sheet migration in response to EGF may therefore contribute to in vivo potentiation of gut mucosal wound healing by EGF (13). Elucidation of the mechanism by which EGF affects integrin organization and pool size awaits better understanding of the mechanisms which modulate integrins. Demonstrations that the EGF receptor phosphorylates such cytoskeletal elements as calpactin II (68), $\alpha$-actinin (6), and myosin (69) are of considerable interest in this regard, as is evidence that the cytoplasmic domain of the $\beta 1$ integrin subunit contains a site homologous to an autophosphorylation site on the EGF receptor (6) and that phosphorylation at this site alters integrin affinity for talin (70). Since laminin is a prominent constituent of gut basement membranes and since both EGF and TGF $\alpha$ appear active in the injured gastrointestinal tract, the stimulation of enterocyte sheet migration over laminin by EGF or TGF $\alpha$ seems likely to contribute to the biological regulation of mucosal wound healing as well as the pharmacological activity of EGF. Research into the pathophysiology of gastrointestinal mucosal healing should consider the regulation of migration as well as proliferation and chemotaxis in analysis of this process.

\section{Acknowledgments}

The provision of the Caco-2 cells for these studies by Dr. M. Mooseker and of antibodies for these studies by Drs. C. Buck, S. J. Kennel, M. Hemler, M. Gallatin, K. Yamada, C. Damsky, and A. Sonnenberg is gratefully acknowledged.

These studies were supported in part by National Institutes of Health ( NIH) grant F-32-DK-08123 (M. D. Basson), NIH grant RO1DK-38063 (I. M. Modlin), and United States Public Health Service grant RO1-HL-28373 (J. A. Madri).

\section{References}

1. Lacy, E. R. 1988. Epithelial restitution in the gastrointestinal tract. J. Clin. Gastroenterol. 10(Suppl. 10):S72-S77.

2. Stenn, K. S., J. A. Madri, and F. J. Roll. 1979. Migrating epidermis produced $\mathrm{AB}_{2}$ collagen and requires continual collagen synthesis for movement. Nature (Lond.). 227:229-232.

3. Barrandon, Y., and H. Green. 1987. Cell migration is essential for sustained growth of keratinocyte colonies: the roles of transforming growth factor- $\alpha$ and epidermal growth factor. Cell. 50:1131-1137.

4. Madri, J. A., B. M. Pratt, and J. Yannariello-Brown. 1988. Matrix driven cell size changes modulate aortic endothelial cell proliferation and sheet migration. Am. J. Pathol. 132:18-27.

5. Kolega, J. 1981. The movement of cell clusters in vitro: morphology and directionality. J. Cell Sci. 49:15-32.

6. Edelman, G. M. 1988. Morphoregulatory molecules. Biochemistry. 27:3533-3543.

7. Bell, L., and J. A. Madri. 1989. The effects of soluble platelet factors on bovine aortic endothelial and smooth muscle cell migration. Circ. Res. 6:10571065.

8. Hunt, T. K., and F. B. La Van. 1989. Enhancement of wound healing by growth factors. N. Engl. J. Med. 321:111-112.

9. Heitz, U., M. Kasper, S. Van Noorden, J. M. Polak, H. Gregory, and A. G. E. Pearse. 1978. Immunohistochemical localization of urogastrone to human duodenal and submandibular glands. Gut. 19:408-413.

10. Wright, N. A., C. Pike, and G. Ellia. 1990. Induction of a novel epidermal growth factor-secreting cell lineage by mucosal ulceration in human gastrointestinal stem cells. Nature (Lond.). 343:82-85.

11. Wan, C. W., M. K. McKnight, D. E. Brattain, M. G. Brattain, and L. C. Yeoman. 1988. Different epidermal growth factor growth responses and receptor levels in human colon carcinoma lines. Cancer Lett. 43:139-143.

12. Beauchamp, R. D., J. A. Barnard, C. M. McCutchen, J. A. Cherner, and R. J. Coffey, Jr. 1989. Localization of transforming growth factor $\alpha$ and its receptor in gastric mucosal cells: implications for a regulatory role in acid secretion and mucosal renewal. J. Clin. Invest. 84:1017-1023.

13. Itoh, M., T. Joh, S. Imai, T. Miyamoto, K. Matsusako, A. Iwai, K. Kat- sumi, K. Endo, K. Goto, and T. Takeuchi. 1988. Experimental and clinical studies on epidermal growth factor for gastric mucosal protection and healing of gastric ulcers. J. Clin. Gastroenterol. 10(Suppl. 1):S7-S12.

14. Lee, H., H.-A. Hanson, E. Norstrom, and H. F. Helander. Immunoreactivities for epidermal growth factor (EGF) and for EGF receptors in rats with gastric ulcers. 1991. Cell Tissue Res. 265:211-218.

15. Brown, G. L., L. Curtsinger III, J. R. Brightwell, D. M. Ackerman, G. R. Tobin, H. C. Polk, C. G. Nascimento, P. Valenzuela, and G. S. Schultz. 1986. Enhancement of epidermal regeneration by biosynthetic epidermal growth factor. J. Exp. Med. 163:1319-1324.

16. Niall, M., G. B. Ryan, and B. M. O'Brien. 1982. The effect of epidermal growth factor on wound healing in mice. J. Surg. Res. 33:164-169.

17. Konturek, S. J., A. Dembinski, Z. Warzecha, T. Brzozowski, and H. Gregory. 1988. Role of epidermal growth factor in healing of chronic gastroduodenal ulcers in rats. Gastroenterology. 94:1300-1307.

18. Olsen, P. S. 1988. Role of epidermal growth factor in gastroduodenal mucosal protection. J. Clin. Gastroenterol. 10(Suppl. 1):S146-S151.

19. Blay, J., and K. D. Brown. 1985. Epidermal growth factor promotes the chemotactic migration of cultured rat intestinal epithelial cells. J. Cell Physiol. 124:107-112.

20. Ruoslahti, E. 1991. Integrins. J. Clin. Invest. 86:1-5.

21. Horwitz, A., E. Duggan, C. Buck, M. C. Beckerle, and K. Burridge. 1986. Interaction of plasma membrane fibronectin receptor with talin-a transmembrane linkage. Nature (Lond.). 320:531-533.

22. Chantret, I., A. Barbat, E. Dussaulx, M. G. Brattain, and A. Zweibaum. 1988. Epithelial polarity, villin expression, and enterocytic differentiation of cultured human colon carcinoma cells: a survey of twenty cell lines. Cancer Res. 48:1936-1942.

23. Chantret, I., G. Trugnan, E. Dussaulx, A. Zweibaum, and M. Rousset. 1988. Monensin inhibits the expression of sucrose-isomaltase in Caco-2 cells at the mRNA level. FEBS (Fed. Eur. Biochem. Soc.) Lett. 235:125-128.

24. Stieger, B., M. Matter, B. Baur, B. Bucher, M. Hochli, and H.-P. Hauri. 1988. Dissection of the asynchronous transport of intestinal microvillar hydrolases to the cell surface. J. Cell Biol. 106:1853-1861.

25. Eilers, U., J. Klumperman, and H.-P. Hauri. 1989. Nocadazole, a microtubule-active drug, interferes with apical protein delivery in cultured intestinal epithelial cells (Caco-2). J. Cell Biol. 108:13-22.

26. LeBivic, A., A. Quaroni, B. Nichols, and E. Rodriguez-Boulan. 1990. Biogenetic pathways of plasma membrane proteins in Caco-2, a human intestinal epithelial cell line. J. Cell Biol. 111:1351-1361.

27. Yannariello-Brown, J., U. Wewer, L. Liotta, and J. A. Madri. 1988. Distribution of a $69 \mathrm{kD}$ laminin binding protein in aortic and microvascular endothelial cells: modulation during cell attachment, spreading, and migration. $J$. Cell Biol. 106:1773-1786.

28. Albelda, S. M., M. Daise, E. Levine, and C. A. Buck. 1989. Identification of and characterization of cell-substrate adhesion receptors on cultured human large vessel endothelial cells. J. Clin. Invest. 83:1992-2002.

29. Kennel, S. J., L. J. Foote, R. Falcon, A. Sonnenberg, C. O. Stringer, C. Crouse, and M. F. Hemler. 1989. Analysis of the tumor-associated antigen TSP180. J. Biol. Chem. 264:15515-15521.

30. Hemler, M. E., F. Sanchez-Madrid, T. J. Flotte, A. M. Krensky, S. J. Burakoff, A. K. Bhan, T. A. Springer, and J. L. Streminger. 1984. Glycoproteins of 210,000 and 130,000 m.w. on activated T cells: cell distribution and antigenic relation to components on resting cells and T cells lines. J. Immunol. 132:30113018.

31. Akiyama, S. K., S. S. Yamada, W.-T. Chen, and K. M. Yamada. 1989. Analysis of fibronectin receptor function with monoclonal antibodies: roles in cell adhesion, migration, matrix assembly, and cytoskeletal organization. J. Cell Biol. 109:863-875.

32. Sonnenberg, A., C. J. T. Linders, P. W. Modderman, C. H. Damsky, M. Aumailley, and $\mathbf{R}$. Timpl. 1990. Integrin recognition of different cell-binding fragments of laminin (P1, E3, E8) and evidence that $\alpha 6 \beta 1$ but not $\alpha 6 \beta 4$ functions as a major receptor for fragment E8. J. Cell Biol. 110:2145-2155.

33. Sonnenberg, A., F. Hogervorst, A. Osterop, and F. E. M. Veltman. 1987. A complex of platelet glycoproteins Ic and IIa identified by a rat monoclonal antibody. J. Biol. Chem. 263:14030-14038.

34. Basson, C. T., W. J. Knowles, S. Albelda, L. Bell, V. Castronovo, L. A. Liotta, and J. A. Madri. 1990. Spatiotemporal segregation of endothelial cell integrin and non-integrin extracellular matrix binding proteins during adhesion events. J. Cell Biol. 110:789-802.

35. Heino, J., and J. Massague. 1989. Transforming growth factor- $\beta$ switches the pattern of integrins expressed in MG- 63 human osteosarcoma cells and causes a selective loss of cell adhesion to laminin. J. Biol. Chem. 24:21806-21811.

36. Choy, M.-Y., P. I. Richman, M. A. Horton, and T. T. MacDonald. 1990. Expression of the VLA family of integrins in human intestine. J. Pathol. 160:3540.

37. Koretz, K., P. Schlag, L. Boumsell, and P. Moller. 1991. Expression of VLA- $\alpha 2$, VLA- $\alpha 6$, and VLA- $\beta 1$ chains in normal mucosa and adenomas of the colon and in colon carcinomas and their liver metastases. Am. J. Pathol. 138:741-750. 
38. Kucik, D. F., S. C. Kuo, E. L. Elson, and M. P. Sheetz. 1991. Preferential attachment of membrane glycoproteins to the cytoskeleton at the leading edge of lamella. J. Cell Biol. 114:1029-1036.

39. Lund-Johansen, M., R. Bjerkvig, P. A. Humphrey, S. H. Bigner, D. D. Bigner, and O. D. Laerum. 1990. Effect of epidermal growth factor on glioma cell growth, migration and invasion in vitro. Cancer Res. 50:6039-6044.

40. Hebda, P. A. 1988. Stimulatory effect of transforming growth factor-beta and epidermal growth factor in epidermal cell outgrowth from porcine skin explant cultures. J. Invest. Dermatol. 91:440-445.

41. Morimoto, A., K. Kamura, R. Hamanaka, Y. Sato, N. Shima, K. Higashio, and M. Kuwano. 1991. Hepatocyte growth factor modulates migration and proliferation of human microvascular endothelial cells in culture. Biochem. Biophys. Res. Commun. 179:1042-1049.

42. McNeil, P. L., and S. Ito. 1989. Gastrointestinal cell plasma membrane wounding and resealing in vivo. Gastroenterology. 96:1238-1248.

43. Moore, R., S. Carlson, and J. Madara. 1989. Rapid barrier restitution in an in vitro model of intestinal epithelial injury. Lab. Invest. 60:237-244.

44. Folkman, J., and A. Moscone. 1978. Role of cell shape in growth control. Nature (Lond.). 273:345-349.

45. Carter, W. G., E. A. Wayner, T. S. Bouchard, and P. Kaur. 1990. The role of integrins $\alpha 2 \beta 1$ and $\alpha 3 \beta 1$ in cell-cell and cell-substrate adhesion of human epidermal cells. J. Cell Biol. 110:1387-1404.

46. Larjava, H., J. Peltonen, S. K. Akiyama, S. S. Yamada, H. R. Gralnick, J. Uitto, and K. M. Yamada. 1990. Novel function for beta 1 integrins in keratinocyte cell-cell interactions. J. Cell. Biol. 110:03-815.

47. Guo, M., K. Toda, and F. Grinell. 1990. Activation of human keratinocyte migration on type I collagen and fibronectin. J. Cell Sci. 96:197-205.

48. Marks, R., and T. Nishikawa. 1973. Active epidermal movement in human skin in vitro. Br. J. Dermatol. 88:245-248.

49. Royce, L. S., and B. J. Baum. 1991. Physiologic levels of salivary epidermal growth factor stimulate migration of an oral epithelial cell line. Biochim. Biophys. Acta. 1092:401-403.

50. Thorne, H. J., D. G. Jose, H. Y. Zhang, P. J. Dempsey, and R. H. Whitehead. 1987. Epidermal growth factor stimulates the synthesis of cell-attachment proteins in the human breast cancer cell line PMC42. Int. J. Cancer. 40:207-212.

51. Lee, K., M. Tanaka, C. Shigeno, I. Yamamoto, S. Ohta, K. Rikimaru, M. Hatanaka, and J. Konishi. 1990. Epidermal growth factor stimulates the anchorage-independent growth of human squamous cell carcinomas overexpressing its receptors. Biochem. Biophys. Res. Commun. 168:905-911.

52. Kirchoffer, D., L. R. Languino, E. Ruoslahti, and M. D. Pierschbacher 1990. $\alpha 2 \beta 1$ integrins from different cell types show different binding specificities. J. Biol. Chem. 265:615-618.

53. Elices, M. M., L. A. Urry, and M. H. Hemler. 1991. Receptor functions for the integrin VLA-3: fibronectin, collagen, and laminin binding are differentially influenced by ARG-GLY-ASP peptide and by divalent cations. J. Cell Biol. 112:169-181.

54. Jinno, Y., G. T. Merlino, and T. Pastan. 1988. A novel effect of EGF on mRNA stability. Nucleic Acids Res. 1:4957-4966.

55. Cheresh, D. A., and R. C. Spiro. 1987. Biosynthetic and functional properties of an Arg-Gly-Asp-directed receptor involved in human melanoma cell at- tachment to vitronectin, fibrinogen, and von Willebrand Factor. J. Biol. Chem. 262:17703-17711.

56. Bellas, R. E., R. Bendori, and S. R. Farmer. 1991. Epidermal growth factor activation of vinculin and $\beta 1$-integrin gene transcription in quiescent Swiss 3T3 cells: regulation through a protein kinase C-independent pathway. J. Biol. Chem. 266:12008-12014

57. de Curtis, I., V. Quaranta, R. N. Tamura, and L. F. Reichardt. 1991. Laminin receptors in the retina: sequence analysis of the chick integrin $\alpha 6$ subunit: evidence for transcriptional and posttranslational regulation. J. Cell Biol. 113:405-416.

58. Basson, C. T., M. A. Reidy, and J. A. Madri. 1990. Vascular endothelial and smooth muscle integrins are both differentially modulated by soluble factors and extracellular matrix during atherogenesis. J. Cell. Biochem. 14E:218.

59. Dziadek, M., and R. Timpl. 1985. Expression of nidogen and laminin in basement membranes during mouse embryogenesis and in teratocarcinoma cells. Dev. Biol. 111:372-382.

60. Gabbiani, G., C. Chapponier, and I. Huttner. 1978. Cytoplasmic filaments and gap junctions in epithelial cells and myofibroblasts during wound healing. J. Cell Biol. 76:561-568.

61. Hahn, U., A. Stallmach, E. G. Hahn, and E. O. Riecken. 1990. Basement membrane components are potent promoters of rat intestinal epithelial cell differentiation in vitro. Gastroenterology. 98:322-335.

62. Hahn, U. 1988. Extracellular matrix proteins in small intestinal cell cultures. Scand. J. Gastroenterol. 23(Suppl. 151):70-78.

63. Boyd, D., G. Florent, S. Chakrabarty, D. Brattain, and M. G. Brattain 1988. Alterations of the biological characteristics of a colon carcinoma cell line by colon-derived substrate material. Cancer Res. 48:2825-2831.

64. Henda, A., N. Noguchi, H. Takehara, Y. Ohashi, N. Asuwa, and Y. Mori. 1991. Cooperative enhancement of hyaluronic acid synthesis by combined use of IGF-1 and EGF, and inhibition by tyrosine kinase inhibitor genistein, in cultured mesothelial cells from rabbit pericardial cavity. J. Cell Sci. 98:91-98.

65. Goodlad, R. A., T. J. G. Wilson, W. Lenton, H. Gregory, K. G. McCullogh, and N. A. Wright. 1987. Intravenous but not intragastric urogastrone-EGF is trophic to the intestine of parenterally fed rats. Gut. 28:573-582.

66. Coffey, R. J., A. S. Goustin, A. M. Soderquist, G. D. Shipley, J. Wolfshohol, G. Carpenter, and H. L. Moses. 1987. Transforming growth factor $\alpha$ and $\beta$ expression in human colon cancer lines: implications for an autocrine model. Cancer Res. 47:4590-4594.

67. Thompson, J. S., L. E. Bragg, and S. K. Saxena. 1990. The effect of intestinal resection and urogastrone on intestinal regeneration. Arch. Surg. 125:1617-1621.

68. Blay, J., K. A. Valentine-Braun, J. K. Northup, and M. D. Hollenberg. 1989. Epidermal-growth-factor-stimulated phosphorylation of calpactin II in membrane vesicles shed from cultured A-431 cells. Biochem. J. 259:577-583.

69. Gallis, B., A. M. Edelman, J. E. Casnellie, and E. G. Krebs. 1983. Epidermal growth factor stimulates tyrosine phosphorylation of the myosin regulatory light chain from smooth muscle. J. Biol. Chem. 258:13089-13093.

70. Horwitz, A. F., D. Bozyczko, and C. Buck. 1990. The integrin family and neighbors. In Morphoregulatory Molecules. G. M. Edelman, B. A. Cunningham, and J. P. Thiery, editors. John Wiley \& Sons, Inc., New York. 217-230. 